\title{
Design and Construction of Additional Security Device for House Door Using Arduino Uno Based on Short Message Service
}

\author{
$1^{\text {st }}$ Yuan Reski Wara \\ Faculty of Electricity and Renewable Energy \\ Institute Teknologi PLN \\ Jakarta, Indonesia \\ yuanreskiwara.1315@gmail.com
}

\author{
$2^{\text {nd }}$ Tri Wahyu Oktaviana Putri \\ Faculty of Electricity and Renewable Energy \\ Institute Teknologi PLN \\ Jakarta, Indonesia \\ triwahyu@itpln.ac.id
}

\begin{abstract}
Security is a very important aspect of a house. The level of protection and comfort of the house certainly cannot be separated from how good the security system of the house is. The door is used for the main entrance and exit of the house. When the owner of the house is inside, the door can be locked from the inside with the addition of a slop lock on the door. However, if the owner of the house leaves, the door is only locked using a regular key without any additional keys on the inside of the door. So that the door of the house can be opened only by "lockpick" by an irresponsible person. Such problems can be prevented by installing additional security devices on the door of the house that can be controlled to lock the inside of the door and can provide early warning to homeowners through SMS (Short Message Service) notifications on cell phones. The components used in this system are Arduino Uno microcontroller, Servo Motor, Vibration Sensor (SW-420), Buzzer, Magnetic Switch $M C-38$, and GSM SIM800L V2. The prototype worked well and reach the research's objective.
\end{abstract}

Keywords-Arduino Uno, House Door, Security System, SMS

\section{BACKGROUND}

Security is a very important aspect of a house. The level of protection and comfort of the house certainly cannot be separated from how good the security system of the house is. Based on Indonesia criminal statistics report in 2020, theft and burglary dominated the criminal reports in Indonesia. The condition might happen because the security system of the house is not adequate. It is well-represented in data provided by Indonesia criminal statistics report that the type of security used in residence or houses were dominated by padlocks or locks only. It is about $61.21 \%$, in contrast with the usage of alarm or CCTV camera that are 0.35 and 0.76 respectively [1]. When the house is left by the owner to carry out activities outside the home, whether it's work or going home while on vacation, usually the house is the target of criminal acts of theft and house burglaries who take advantage of the empty house situation.

The door is used for the main entrance and exit of the house. When the owner of the house is inside, the door can be locked from the inside with the addition of a slop lock on the door. However, if the owner of the house leaves, the door is only locked using a regular key without any additional keys on the inside of the door. So that the door of the house can be opened only by "lockpick" by an irresponsible person. The door can also be broken in to damage the door hinges. Often homeowners do not realize that the door of their house is broken and opened and valuables stolen by the perpetrators of theft.
The development of security system technology today is very helpful to reduce the crime of theft and house burglary. One technology that can reduce these problems is by designing an additional security device on the door of the house with an SMS (Short Message Service). The idea of additional security devices were successfully designed and built based on SMS by [2]. There was a research about home security system with the addition of intruder detection system [3]. The usage of GSM module for the security system were also successfully implemented by [4], [5], [6], [7].

This research is focused on implementing and designing an additional security device on the door of the house with an SMS (Short Message Service). This additional safety device can be activated when the homeowner wants to move outside the home by accessing a cellular phone and sending a short message to the number installed on the GSM SIM800L V2 module to close or open an additional lock on the inside of the house door. So that homeowners will feel safe to travel to do activities outside the home. The prototype designed is expected to help homeowners feel safer when the house is left for outdoor activities because the tool will provide direct notifications on the homeowner's mobile phone if the door of the house is broken or forced open by an irresponsible person. The components used in this system are Arduino Uno microcontroller, Servo Motor, Vibration Sensor (SW420), Buzzer, Magnetic Switch MC-38, and GSM SIM800L V2. Magnetic switch is capable enough for home security system like the research done by [8].

\section{RESEARCH METHODS}

This study uses experimental quantitative research methods because the implementation includes system analysis and system design. In this study, a prototype of an additional security device at the door of the house will be designed using an Arduino Uno based on SMS (Short Message Service).

\section{A. Method of Collecting Data}

The data collection method is one of the stages of detailed and specific research planning on how to obtain, process, and analyse the data obtained. Prototyping and tool testing are the methods used in this research. The research stages of the design of the tool "Design of Additional Security Devices on the Door of the House Using SMSBased Arduino Uno"(Short Message Service)" which starts from literature study, prototype making, tool testing, data collection needed, tool analysis, and report writing. 


\section{B. Data Analysis Method}

In the research "Design of Additional Security Devices at the Door of the House Using Arduino Uno Based on SMS (Short Message Service)", an analysis of the experiment or testing of the tool was carried out to see how the device worked. Some of the indicators that must be analyzed are:

- Tool

Prototyping that has been done by assembling or assembling the components needs to be analyzed whether it is in accordance with the initial description of the tools and programs used, it needs to be checked so that when an error occurs or an error in the performance of the tool can be corrected immediately.

\section{- System Performance}

The system performance that needs to be analyzed is the time (delay) from the vibration sensor, magnetic switch, and buzzer to send alert notifications via the GSM SIM800L V2 module to the cellular phone. Then time (delay) of the servo motor to be able to switch positions based on SMS sent from cell phones.

\section{Research Design}

In designing research tools, several components are needed to support this research, both from hardware (Hardware) and software (Software). The following hardware components are needed in the design:

- Arduino Uno Microcontroller

- GSM SIM800L V2

- $\quad$ SG90 . servo motor

- Vibration sensor (vibration sensor)

- Magnetic Switch

- buzzer

- 12 Volt Adapter

- $\mathrm{DC}$ to DC regulator

Apart from hardware (Hardware), tool design also uses software (Software). The following software components are needed in the design:

- $\quad$ Arduino IDE

- SMS gateway

\section{RESULTS AND DISCUSSION}

In research which is the manufacture of tools from several components that have their respective functions for performance in accordance with the description of the tool, it is necessary to test each component. The components that are arranged in the design consist of a vibration sensor (Vibration Sensor SW-420), Magnetic Switch MC-38, Servo Motor SG90 and GSM SIM800L V2..

\section{A. Vibration Sensor Testing (Vibration Sensor SW-420)}

The SW-420 sensor module is a sensor that can detect vibrations from the outside. The workings of this sensor is from one metal float in a tube containing two electrodes that will vibrate when the sensor module detects a vibration. There are 2 outputs, namely digital outputs ( 0 and 1$)$ and analog outputs. Vibration sensor testing is done by connecting the sensor with the Arduino Uno digital pin whose input value will be forwarded to the output component in the form of a buzzer or electronic component that can convert electrical signals into sound signals which are commonly referred to as alarms. Observations were made to see the response of the sensor that was given a vibration with a knock and a crash on the sensor placement media in the form of a simple door design that would give a signal to the buzzer.

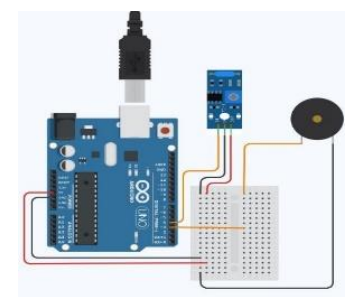

Fig. 1. Vibration sensor circuit with buzzer

The vibration sensor (Vibration Sensor SW-420) has 3 pins consisting of the data pin, the GND pin (-) and the VCC (+) pin. In Figure 1 the data pins are connected directly to the digital pin 4 of the Arduino Uno, while the GND and VCC pins are connected to the breadboard which had previously been connected to the VCC and GND of the Arduino Uno. The buzzer has 2 legs, namely the (-) leg connected to the GND breadboard and the (+) foot connected to the Arduino Uno digital pin 3. When the vibrating sensor detects a vibration, the indicator LED on the vibration sensor will flash quickly as a result of the vibrating electrode. The results of the vibration sensor test can be seen in Table I.

TABLE I. VIBRATION SENSOR TEST

\begin{tabular}{|c|c|c|}
\hline Vibration & $\begin{array}{c}\text { Vibration } \\
\text { Sensor }\end{array}$ & Buzzer \\
\hline Nothing & No Detect & Not active \\
\hline Knock & Detection & Active \\
\hline Break through & Detection & Active \\
\hline
\end{tabular}

\section{B. Magnetic Switch MC-38 Testing}

The MC-38 detects open or close doors, works based on electromagnetic principles [8]. That way, the way the MC-38 works is the same as a switch. The output of the MC-38 is in the form of digital data. The MC-38 module has two legs, namely the output leg and the GND. One pin of the MC-38 sensor must be connected to the Arduino digital pin and the GND pin must be connected to the Arduino GND pin. The MC-38 sensor will detect an opening from a door or window which when closed will be logic 0 (LOW) and when open will be logic 1 (HIGH). Magnetic Switch Sensor MC-38 is used in the design as a detector for openings in house doors. When the door of the house is open, the Magnetic Switch MC-38 sensor sends a logic 1 signal to activate the buzzer or alarm via the Arduino Uno microcontroller.

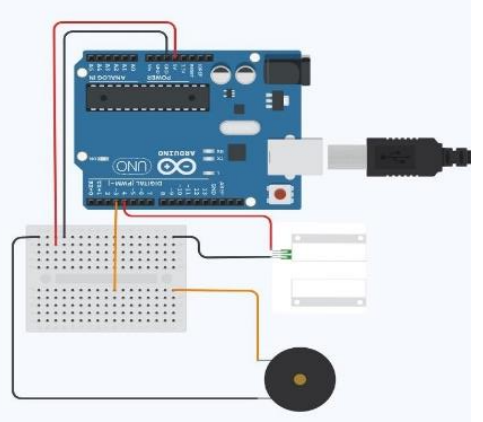


Fig. 2. Magnetic switch circuit with buzzer

Magnetic Switch Sensor MC-38 has 2 legs in the form of legs (+) and feet (-). Just like a buzzer which has the same 2 legs with (+) and (-) signs. The positive leg of the sensor will be connected to digital pin 4 of the Arduino Uno and the negative leg is connected to GND on the breadboard, while the positive leg of the buzzer is connected to digital pin 3 of the Arduino Uno and the negative leg is connected to GND on the bread broad. Sensor test results can be seen in Table II.

TABLE II. MAGNETIC SWITCH TEST

\begin{tabular}{|c|c|c|}
\hline Door & Sensor & Buzzer \\
\hline Closed & No Detect & Not active \\
\hline Open & Detection & Active \\
\hline
\end{tabular}

\section{Servo Motor SG90 Testing}

Servo motors use a closed feedback system, where the position of the motor will be forwarded back to the control circuit in the motor [9]. Servo motors are composed of a DC motor, a series of gears, a potentiometer and a control circuit. There are 2 types of servo motors in general, namely standard servo motors and continuous servo motors. A standard servo motor can only rotate 180 degrees. Standard Servo Motors are widely used in robotic systems, for example in the manufacture of "Robot Arm". Meanwhile, the continuous servo motor can rotate 360 degrees. Continuous Servo Motors are often applied to Mobile Robots.

Servo motor in this study is used as a door slop controller. Before the servo motor is installed on the door slop, it is necessary to test the rotation angle of the servo motor. Apart from the rotation angle of the servo motor, the influence of the voltage source will also be tested. In testing the servo motor, the component that controls the direction of rotation of the servo motor used is the push button. Observations were made when the push button was pressed and simultaneously saw the response of the push button to the direction of rotation of the servo motor. When the push button condition is pressed, the source voltage will be disconnected to observe the servo motor response when there is no input voltage. To be able to program servo motors, a special library is needed for programming, namely by entering the include<Servo.h $>$ header. The servo motor circuit can be seen in Figure 3.

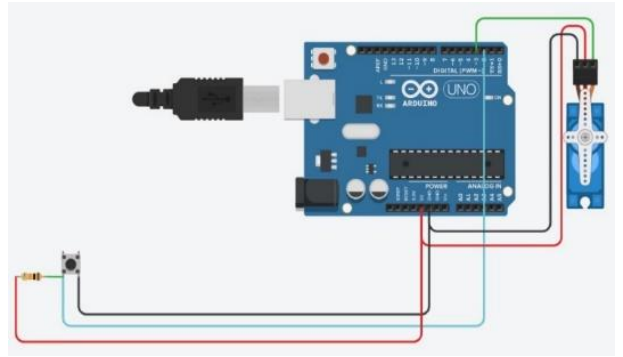

Fig. 3. Servo motor circuit with push button

In Figure 3 the servo motor has 3 pins consisting of the data pin, the VCC (+) pin and the GND pin (-). These pins are connected to the Arduino Uno according to their respective pins. While on the push button only 2 feet are connected to the Arduino Uno. The servo motor data pin is connected to the Arduino Uno digital pin 3, the VCC (+) and GND (-) pins are connected to the Arduino Uno's VCC (+) and GND (-) pins. The servo motor will be controlled by the rotation angle by the input from the push button. Can be seen Table III for servo motor testing.

TABLE III. SERVO MOTOR TESTING

\begin{tabular}{|c|c|c|}
\hline $\begin{array}{c}\text { Voltage } \\
\text { Source }\end{array}$ & $\begin{array}{c}\text { Push } \\
\text { Button }\end{array}$ & $\begin{array}{c}\text { Motor } \\
\text { Servo SG90 }\end{array}$ \\
\hline Yes & Removed & Not moving \\
\hline Yes & Pressed & Rotating $90^{\circ}$ \\
\hline No & Removed & Stand still at $90^{\circ}$ \\
\hline No & Pressed & Stand still at $90^{\circ}$ \\
\hline Yes & Removed & $\begin{array}{c}\text { Rotate To Starting } \\
\text { Position }\end{array}$ \\
\hline
\end{tabular}

\section{Testing GSM SIM800L V2}

The GSM SIM800L V2 module is a module that is specifically designed as a system that processes SMS or calls from cellular phones which will later be programmed on certain SMS texts that can provide signals to the output components using SMS Gateway software. SMS (Short Message Service) Gateway is software that requires a system from a computer and uses combined cellular technology to be able to forward messages that have passed through the information system with SMS media handled by a cellular network provider. SMS is set on a text data service or SMS Center (SMSC) which is useful for storing and forwarding messages from the sender's location to the recipient's location. The GSM module requires sufficient source voltage to get the signal from the SIM card. So that the test will use a DC to DC regulator as a regulator of the incoming input voltage to be issued and connected directly to the SIM800L V2 module.

In the design of additional security devices on the door of the house, SIM800L V2 is used as the main component to control the opening and closing of the door slop, providing notifications obtained from the vibration sensor and the opening sensor. So that before being used in the design tool, it is necessary to observe the workings of the GSM SIM800L V2 module for sending and receiving SMS. Tests carried out on GSM SIM800L V2 are with a control program for the LEDs that can be turned on and off via SMS commands. The series of testing of the GSM SIM800L V2 module can be seen in Figure 4.

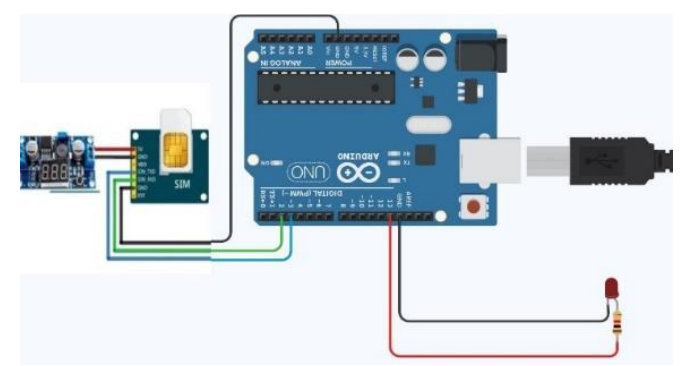

Fig. 4. SIM800L V2 Circuit With led

The GSM SIM800L V2 module has 7 pins, namely the VCC (+) and GND (-) pins which function as input voltage 
pins from the regulator. The VDD pin or the $5 \mathrm{Vdc}$ voltage reference pin, the TX pin as a serial transceiver or data transmission and the RX pin as a serial receiver or data receiver. The GND (-) pin is connected directly to the Arduino Uno to enable the TX and RX pins. The RST (reset) pin that functions as a module reboot or restores the module to its initial state.

Of the seven pins on the GSM SIM800L V2 module, only the TX pin, RX pin and GND pin are connected to the Arduino Uno. The TX pins and RX pins are connected opposite each other on the Arduino digital pins programmed as TX and RX. In the test, Arduino pin 2 functioned as TX which was connected to the RX pin of the SIM800L V2 module, while Arduino pin 3 functioned as RX which was connected to the TX pin of the SIM800L V2 module. For the LEDs used are directly connected to the Arduino digital pin 13. The results of the SIM800L V2 module testing can be seen in Table IV.

TABLE IV. GSM800L V2 SIM TESTING

\begin{tabular}{|c|c|c|c|}
\hline $\begin{array}{c}\text { Signal } \\
\text { GSM }\end{array}$ & SMS & LED & $\begin{array}{c}\text { Delay } \\
\text { (second) }\end{array}$ \\
\hline No & On & off & - \\
\hline No & Off & off & - \\
\hline Yes & On & on & 0.6 \\
\hline Yes & Off & off & 0.8 \\
\hline
\end{tabular}

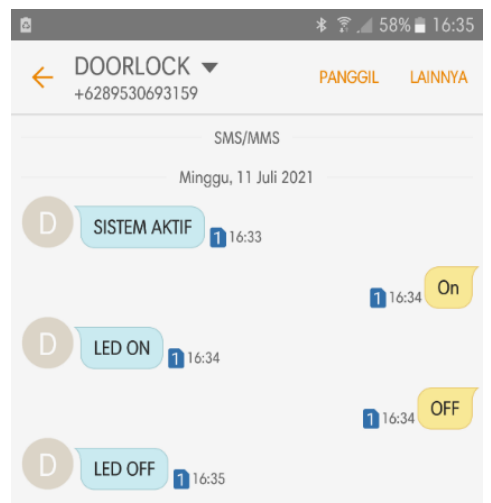

Fig. 5. Testing SMS SIM800L V2

\section{E. Overall Result of Tool Work System}

After all components are tested to obtain data that can be observed how the components that will be used in the design of additional security devices on the door of the house are designed, then all components will be connected according to the program designed with the circuit shown in Figure 6.

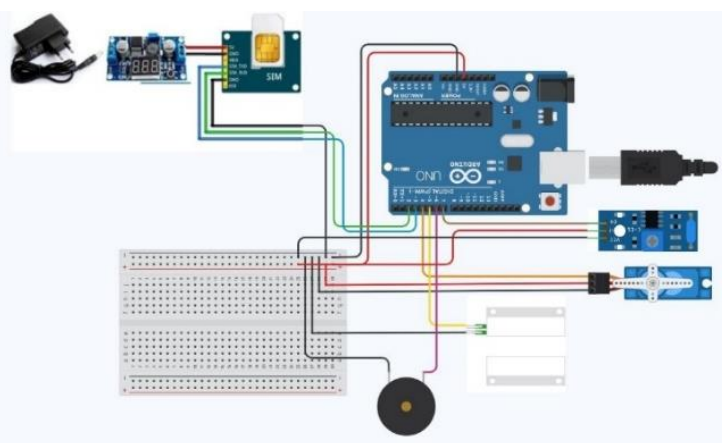

Fig. 6. The overall circuit of additional safety devices
Each component is connected by a jumper to the Arduino digital pin. As when testing the components used are connected according to their respective pins. However, in the design of additional safety devices at the door of the house, the voltage source from the $12 \mathrm{~V}$ adapter is paralleled with the regulator as a voltage regulator for the GSM SIM800L V2 module. The GSM SIM800LV2 module will be the controlling component to receive and send the results of system processing that has been carried out by additional security devices on the door of the house. The servo motor will rotate automatically after the GSM module receives the SMS that has been determined by the program and there will be a reply SMS after the servo motor moves or locks the door. As for the aperture sensor, it will send notifications in the form of incoming calls to the homeowner's cellular phone. When the aperture sensor detects the door is open, the buzzer will automatically sound. The buzzer will be turned off when GSM receives certain SMS. The vibration sensor if it detects a vibration on the door will send a notification that someone is trying to enter. Testing of servo motor with open and close control by GSM module can be seen in Table V.

\begin{tabular}{|c|c|c|c|}
\hline $\begin{array}{c}\text { Text Message } \\
\text { (SMS) }\end{array}$ & $\begin{array}{c}\text { Condition } \\
\text { Servo } \\
\text { Motor }\end{array}$ & $\begin{array}{c}\text { delay } \\
\text { (second) }\end{array}$ & $\begin{array}{c}\text { Notifications } \\
\text { (SMS) }\end{array}$ \\
\hline TUTUP & Close & 1.12 & CLOSED \\
\hline BUKA & Open & 0.74 & OPEN \\
\hline
\end{tabular}

From the test results, it can be seen that the servo motor works according to the commands sent via SMS from the homeowner's mobile phone to close and open the door lock slop as shown in Figures 7 and 8.

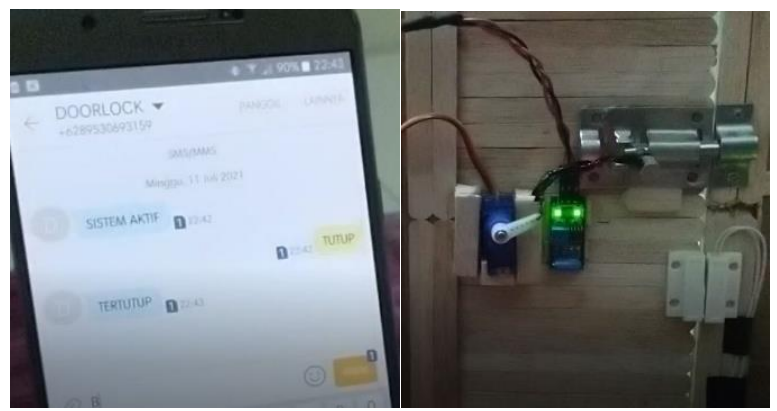

Fig. 7. Close command and servo closing result notification

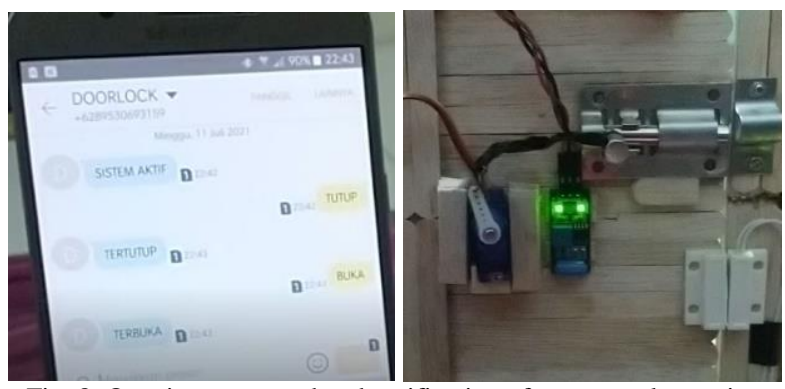

Fig. 8. Opening command and notification of servo result opening

When the door is open, the system for the vibration sensor and the opening sensor will not work. Because the open and close system is designed as a switch for other sensors in order to control the whole system of sensor work. If the door slop or servo motor is closed (position $90^{\circ}$ ), then the system as a whole can work as shown in Table VI. 


\begin{tabular}{|c|c|c|c|}
\hline $\begin{array}{c}\text { Condition } \\
\text { Servo Motor }\end{array}$ & $\begin{array}{c}\text { Sensor } \\
\text { Vibrate }\end{array}$ & $\begin{array}{c}\text { delay } \\
\text { (second) }\end{array}$ & $\begin{array}{c}\text { Notifications } \\
\text { (SMS) }\end{array}$ \\
\hline Closed & Detection & 0.67 & $\begin{array}{c}\text { Someone is } \\
\text { trying to break } \\
\text { into the house }\end{array}$ \\
\hline Open & Detection & - & - \\
\hline
\end{tabular}

From the test results when the door slop is closed and the condition of the vibration sensor detects a vibration that occurs at the door, there will be a notification to the cellular phone with a time span of less than 1 second.

If the door is closed or the servo motor position is at (position $90^{\circ}$ ) as shown in Figure 7 , the aperture sensor or magnetic switch and buzzer can work when the door is open. The following table VII results from testing the opening sensor on additional security devices on the door of the house.

TABLE VII. SMS CONTROL SERVO MOTOR TESTING

\begin{tabular}{|c|c|c|c|c|c|c|}
\hline \multicolumn{1}{c}{ TABLE VII. SMS CONTROL SERVO MOTOR TESTING } \\
\begin{tabular}{|c|c|c|c|c|}
\hline Servo \\
Motor
\end{tabular} & Door & $\begin{array}{c}\text { SMS } \\
\text { Command } \\
\text { From } \\
\text { Mobile }\end{array}$ & $\begin{array}{c}\text { Magnetic } \\
\text { Switch }\end{array}$ & buzzer & $\begin{array}{c}\text { Notificati } \\
\text { ons }\end{array}$ & $\begin{array}{c}\text { delay } \\
\text { (second) }\end{array}$ \\
\hline Closed & Open & - & Detection & on & $\begin{array}{c}\text { Incomin } \\
\text { g call }\end{array}$ & 30 \\
\hline Closed & Open & OFF & No Detect & off & $\begin{array}{c}\text { SMS ALAR } \\
\text { M_OFF }\end{array}$ & 1.62 \\
\hline Open & Open & - & Detection & off & - & - \\
\hline
\end{tabular}

The working system of additional safety devices on this door works when the door slop is in a closed condition which is controlled by a servo motor with commands or instructions from an incoming SMS on the GSM SIM800L V2 module which will also provide a notification when the command has been completed. In Table VII it can be seen that the aperture sensor will work when the door slop condition is closed. When the sensor detects it automatically, the buzzer sounds immediately and an incoming call to the mobile phone will start with a 30 second timeframe for the next call. Then to turn off the alarm sound, controlled by a specific SMS message. Because when the sensor works, GSM makes calls, the time it takes to turn off the alarm sound is quite long compared to other SMS commands.

In Figure 9 it can be seen that the condition of the door is closed which means the position of the servo motor is position 900 which activates the working system of the sensor components as a whole. When the door is opened, part of the aperture sensor will move away from the other. Then automatically activate the buzzer and the GSM SIM800L V2 module will process the command to send an incoming call to the cellular phone number that has been inputted in the additional security device program on the door of the house as shown in Figure 10.

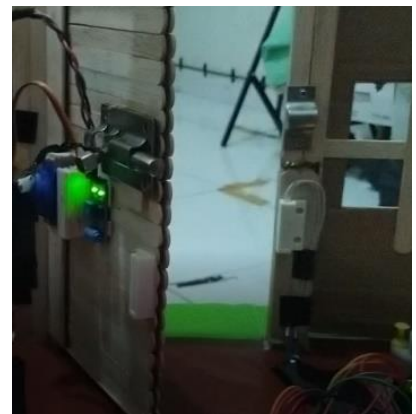

Fig. 9. The condition of the servo is closed, the door is open, and the magnetic switch detects.

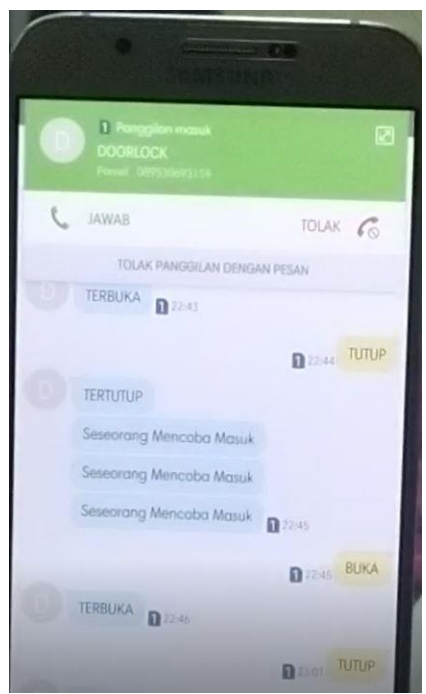

Fig. 10. GSM SIM800L V2 making an incoming call

The alarm state when the GSM SIM800L V2 module makes an incoming call to a cellular phone is still active. To turn off the alarm sound that arises due to the sensor detecting the opening, the cellular phone will send a certain SMS, namely "OFF". With a fairly long time span due to processing between incoming calls and turning off the buzzer alarm, the time interval to make the buzzer turn off is longer when compared to processing other components when given an SMS command from the cellular phone to the GSM SIM800L V2 module.

\section{F. Discussion}

The tests that have been carried out are to find out how the components that will be used work to the testing of all components that have been connected to become a prototype for additional security devices on the door of the house. From the component testing carried out, it can be seen from Table I for testing the vibration sensor to work well in accordance with the existing theory in this study. The working vibration sensor will be connected to the Arduino and functioned as a detector if someone tries to enter the house to damage the door by banging and breaking the door. The vibration sensor on the device becomes an early notification before the door is forcibly opened by irresponsible people when the homeowner leaves the house to do activities outside the home. Thus, homeowners do not worry about people trying to enter the house. If there is a notification that someone is trying to enter, the homeowner can immediately anticipate it by contacting neighbors or the authorities quickly. 
Then testing on the aperture sensor or Magnetic Switch as shown in table II with results that match the theory and workings of the sensor. The aperture sensor is used as a detector on the door of the house if the door slop is damaged and the door is forced open until it opens, then the aperture sensor will immediately activate a buzzer which will issue an alarm sound for direct warning that someone has forced the door open and forcibly entered the house. Apart from activating the buzzer, the aperture sensor will also send a notification to the homeowner with the GSM SIM800L V2 module running an incoming call program to the homeowner's number. Thus, the homeowner will immediately receive a notification if the house has been entered by an irresponsible person.

Tests carried out on the servo motor to show whether the servo motor can be controlled in the direction of the rotation angle. In table III, it can be seen that the servo motor works according to the program uploaded on the Arduino Uno. Servo motors are used in additional tools on the door of the house as a control to open and close the door slop of the house when the homeowner will leave the house to do activities outside the home. The servo motor will be connected to the GSM SIM800L V2 module which will be given an order from a certain SMS to carry out the process of changing the motor angle which is associated with the door lock slop. The test results also show that when the servo motor is in position 900 without a voltage source, the servo motor maintains its position until the input conditions are changed and the source voltage is returned. The test is carried out so that when the door has been locked with a door slop controlled by the servo motor, it does not get a voltage source, the lock does not open and maintains its position so as not to return to the servo motor's initial position. The servo motor is also used as a switch to activate the work system of all the sensors used. If the door slop condition is open or the servo motor is in position 00 , then the sensor component will not work even if a trigger is given for the sensor to detect it. However, if the condition of the door slop is closed or the position of the servo motor is at position 900 , then the working system of the sensor will be active and can provide an input signal that will be sent to the Arduino Uno then processed and forwarded to the output component.

Testing on the GSM SIM800L V2 module with commands from the cellphone by sending an SMS to turn the LED on and off is shown in table IV. The GSM SIM800L $\mathrm{V} 2$ module will work on a $5 \mathrm{~V}$ voltage and to get a signal the SIM800L V2 GSM module requires a voltage of $5.5 \mathrm{~V}$ in order to receive and send SMS. To obtain a sufficient voltage, a $12 \mathrm{~V}$ adapter and a DC to DC regulator are used as input voltage reducers whose output voltage can be adjusted. After the input voltage to the GSM SIM800L V2 module is sufficient to obtain a signal from the card used, the module is ready for use. In the tests carried out, when the GSM SIM800L V2 module does not get a signal or SIM card network, the SMS sent by the cellphone to turn on the LED cannot be forwarded for processing. However, When the GSM SIM800L V2 module has received a SIM card network signal, the SMS sent to the cellphone can be forwarded to run the program according to the function of the SMS that has entered the GSM SIM800L V2 module. The program to turn on the LED is by sending an "On" SMS from the cellphone to the GSM module. After the GSM module receives the SMS, it will be forwarded to the Arduino Uno for processing according to the uploaded program. If the
SMS sent is the same as the SMS that has been programmed, the LED will light up. When the LED is on, there is a reply from the GSM module to the cellular phone in the form of an SMS "LED ON". Likewise when turning off the LED with the SMS command "OFF" from the cellphone sent to the GSM module. After the LED is off, there will be a reply SMS that goes to the cellphone in the form of an SMS "LED OFF". Thus, from the test results on the GSM SIM800L V2 module, it can be used as a communication tool that can control and give direct warnings to homeowners. The GSM SIM800L V2 module will be used and connected to the vibration sensor, aperture sensor, servo motor, and buzzer. Each component will be given a certain program so that it can be given an order or give a direct notification to the mobile number that is used to control the additional security device for the house door. The vibration sensor will only provide notifications to the user's cellphone, the aperture sensor or magnetic switch provides different notifications from the vibration sensor, namely by providing direct incoming call notifications. The servo motor will be controlled to open and close the door slop by SMS "CLOSE" and "OPEN". While the buzzer is used to turn off the sound caused by the opening sensor detecting an open door by sending an "OFF" SMS. Every SMS that is sent to the GSM module, there will be a direct reply to the user's cell phone.

After all components are tested and obtained results in accordance with the theory contained in this study, then all these components are connected and assembled according to the circuit in the figure above. After all components are connected and assembled properly according to their respective pins, then upload the program to the Arduino Uno. In table V, the servo motor which is controlled by SMS is tested on the mobile phone to the GSM SIM800L V2 module. The servo motor can work properly according to the command sent and notify when it has finished carrying out the command. Then the vibration sensor is tested to provide notification if someone tries to enter or damage the door. In table VI, it can be seen that the vibration sensor works according to its function on additional security devices at home by providing notifications in the form of SMS to the cell phone. Then testing is carried out for the aperture sensor and buzzer which functions as an early warning when the door has been tampered with and opened by irresponsible person. Table VII shows the test results when the door is opened, the aperture sensor will detect and immediately send a signal to activate the buzzer, thus issuing an alarm sound as an early warning. When the sensor detects, the GSM SIM800L V2 module will send a notification in the form of an incoming. For the buzzer that still emits a warning sound,

From the results of the overall test carried out, the design of additional security devices on the door of the house using Arduino Uno based on SMS (Short Message Service) went as expected. Each component works well and is able to provide results in accordance with the commands given.

\section{CONCLUSION}

The design of additional security devices on the door of the house using Arduino Uno based on SMS (Short Message Service) is carried out in stages. Before designing the tool, first obtain theoretical knowledge about the topic of door security using Arduino Uno from previous journals in order to develop or update a security system on the door of the house. Then look for components that will be used in the 
design of the tool. After the components that will be used in the design have been collected, it is necessary to know what kind of testing and what components need to be tested. There are several important components in the design of this additional safety device, namely the GSM SIM800L V2 module, Servo Motor, Vibration Sensor and Magnetic Switch. All these components are tested according to their function on the safety device on the door of the house. After all have been tested and the data obtained from the test results, the components are assembled and connected according to their respective pins.

Reliability of additional security devices on the door of the house using Arduino Uno based on SMS (Short Message Service) can be seen from the results of testing the overall performance of the tool that has been assembled and connected to each pin on the Arduino Uno. The working system of additional safety devices on this door is when the servo motor has been given an order in the form of SMS "CLOSE" then all components can work. The vibration sensor is used as a warning signal that when the vibration sensor detects vibrations around the door, there will be a notification in the form of an SMS "Someone is trying to enter" sent by the GSM SIM800L V2 module. Then a magnetic switch is used as a detector if the door of the house has been opened and will automatically give an input signal to the buzzer to give an early warning in the form of an alarm sound directly. A notification that is sent when the magnetic switch detects an opening is an incoming call to the mobile number that has been inputted in the program. While the buzzer that is still on will be turned off by sending an "OFF" SMS, when the buzzer has gone out there will be a reply indicating the buzzer has been successfully turned off, namely the "ALARM_OFF" SMS. The test was carried out and obtained results that can be observed that the additional security device on the door of the house uses an SMS-based Arduino Uno (Short Message Service) can work according to the flow chart that has been designed. All components work according to the functions specified in the program and sensors can detect them quickly.

\section{REFERENCES}

[1] BPS-Statistic Indonesia, “Criminal Statistics 2020,” Jakarta.

[2] B. Choudhury, T. S. Choudhury, A. Pramanik, W. Arif, and J. Mehedi, "Design and implementation of an SMS based home security system," 2015. doi: 10.1109/ICECCT.2015.7226115.

[3] G. C. Nwalozie, A. N. Aniedu, C. S. Nwokoye, and I. E. Abazuonu, "Enhancing Home Security Using SMS-based Intruder Detection System,” 2015.

[4] A. S. Parab and A. Joglekar, "Implementation of Home Security System using GSM module and Microcontroller GSM(Global System for Mobile Communications), Microcontroller, SMS, security," 2015. [Online]. Available: http://ijcsit.com/docs/Volume 6/vol6issue03/ijcsit20150603212.pdf.

[5] K. W. Chan, R. Teymourzadeh, M. I. Iet, S. A. Ahmed, K. W. Chan, and M. V. Hoong, "Smart GSM based Home Automation System Smart GSM Based Home Automation System,” 2015.

[6] Arijit Pal, Akanksha Singh, and Bijay Rai, "GSM Based Home Automation, Safety and Security System Using Android Mobile Phone," 2015. doi: 10.17577/ijertv4is050648.

[7] S. Budijono, J. Andrianto, and M. Axis Novradin Noor, "Design and implementation of modular home security system with short messaging system," 2014. doi: 10.1051/epjconf/20146800025.

[8] S. Siswanto, G. P. Utama, and W. Gata, "Pengamanan Ruangan Dengan Dfrduino Uno R3, Sensor Mc-38, Pir, Notifikasi Sms, Twitter," 2018. doi: 10.29207/resti.v2i3.592.

[9] A. Rahman, “Assignment on Servo Motor," 2018. doi: 10.13140/RG.2.2.10036.35206 